\title{
Esophageal Adenocarcinoma Developing after Eradication of Helicobacter pylori
}

\author{
Yasuhiko Abe Tomoyuki Koike $^{a}$ Katsunori lijima ${ }^{a}$ \\ Akira Imatani $^{\mathrm{a}}$ Kazuhiko Ishidac Toyohiko Yuki $^{\mathrm{d}}$ \\ Go Miyatab Tooru Shimosegawa ${ }^{a}$
}

Divisions of a Gastroenterology and ${ }^{\mathrm{b}}$ Advanced Surgical Science and Technology, Tohoku University Graduate School of Medicine, Ishida Clinic, and dYuki Clinic, Sendai, Japan

\section{Key Words}

Helicobacter pylori eradication · Esophageal adenocarcinoma

\begin{abstract}
A 75-year-old man underwent endoscopic hemostatic therapy for hemorrhagic gastric ulcer in September 2002. After healing of the gastric ulcer, he underwent Helicobacter pylori eradication therapy in February 2003. In August 2007, an irregular tumor was detected in the lower esophagus at annual checkup for gastric cancer screening using $\mathrm{X}$-ray. Endoscopic examination showed that the lower margin of the tumor almost coincided with the esophagogastric junction and that a short segment of Barrett's epithelium existed near the tumor. Biopsies of the tumor showed moderately to poorly differentiated adenocarcinoma. Mild reflux esophagitis and minor hiatal hernia was also observed, and the previously treated gastric ulcer was not recurrent. Absence of $H$. pylori was confirmed by serum antibody and urea breath test. Surgical resection of the lower esophagus and proximal stomach was performed. The tumor invaded into the muscularis propria of the esophageal wall but had no evidence of lymph node metastasis. Based on macroscopic and pathological findings, the tumor was recognized as esophageal adenocarcinoma. Previous endoscopic examination did not detect any apparent signs of tumor in the esophagogastric junction. As far as we know, this is the first report documenting a newly developed esophageal adenocarcinoma after the successful eradication of $H$. pylori.
\end{abstract}




\section{Introduction}

Previous reports have demonstrated that Helicobacter pylori infection is significantly less prevalent in patients with gastroesophageal reflux disease (GERD) compared to control subjects without GERD, indicating that $H$. pylori infection has a potentially protective role in the development of GERD [1]. This protective role is cancelled by the successful eradication of $H$. pylori, which can lead to an increase in newly developing GERD at least in some areas such as Asian countries [2-6]. GERD is a well-known risk factor for complications such as Barrett's esophagus or esophageal adenocarcinoma [7], so there has been concern that the de novo development and the persistence of GERD after $H$. pylori eradication may result in increased risk for esophageal adenocarcinoma. Until now, the long-term course of newly developing GERD after $H$. pylori eradication remains unknown, and there has been no report documenting a case who developed esophageal adenocarcinoma after eradication therapy. Herein we report the first case of esophageal adenocarcinoma developing after $H$. pylori eradication.

\section{Case Report}

A 75-year-old man underwent endoscopic hemostatic therapy (pure ethanol injection method) for hemorrhagic gastric ulcer of the gastric body in September 2002. After healing of the gastric ulcer, the patient was diagnosed to be infected with $H$. pylori by serum antibody and urea breath test. $H$. pylori eradication therapy was performed using lansoprazole $30 \mathrm{mg}$, amoxicillin $750 \mathrm{mg}$ and clarithromycin $200 \mathrm{mg}$ twice daily for a week in February 2003. Eradication was confirmed successful by urea breath test, and he was able to cease taking regular medication in August 2003.

In August 2007, he underwent an examination for gastric cancer screening using X-ray. An irregular tumor approximately $3 \mathrm{~cm}$ in diameter was detected in the lower esophagus, so he consulted our hospital for further examination and treatment. He had neither had any upper abdominal symptoms nor acid-suppressive therapy since the previous treatment for gastric ulcer. Endoscopic examination showed that the tumor was located in the 1 o'clock position of the lower end of the esophagus (fig. 1a), and the lower margin of the tumor almost coincided with the esophagogastric junction (fig. 1b). A short segment of columnar-lined esophagus with squamous islands (short-segment Barrett's epithelium) was observed in the 11 o'clock position of the esophagogastric junction near the tumor (fig. 1c). Biopsies of the tumor showed moderately to poorly differentiated adenocarcinoma. Mild reflux esophagitis corresponding to Los Angeles grade A, minor hiatal hernia and scarring from the previously treated gastric ulcer were also present. Absence of $H$. pylori was confirmed by serum antibody and urea breath test.

Surgical resection of the lower esophagus and the proximal stomach was performed in November 2007. In the resected samples, the tumor was localized in the lower end of the esophagus as observed by endoscopy (fig. 2a). Pathological examination showed that the tumor invaded into the muscularis propria of the esophageal wall but had no evidence of lymph node metastasis. Intestinal metaplasia and submucosal esophageal glands were histologically confirmed in the coexistent short segment of Barrett's epithelium near the tumor (fig. 2b). Retrospective assessment of previous endoscopic examination performed in December 2002 prior to eradication therapy did not show any apparent signs of tumor in the lower esophagus (ig. $)$. Thus, the tumor was considered as a newly developed esophageal adenocarcinoma after the successful eradication of $H$. pylori.

\section{Discussion}

In this case report, we describe a male patient with newly developed esophageal adenocarcinoma discovered 5 years after the eradication of $H$. pylori. No evidence of this 
tumor was found in the previous endoscopic examination performed before and immediately after eradication therapy.

Labenz et al. [8] previously reported an alarming observation that reflux esophagitis newly developed in up to $26 \%$ of patients with duodenal ulcer after the clearance of H. pylori, whereas it was present only in $13 \%$ of those with persistent infection. Barrett's esophagus and adenocarcinoma related to it have been recognized as a complication of GERD [7], so their report raised a special concern that H. pylori eradication therapy may be a potential risk factor for developing esophageal adenocarcinoma. Thus far, there has been no report documenting newly developed esophageal adenocarcinoma after eradication therapy. Although many studies have been conducted to address the relation between GERD and H. pylori eradication, whether or not GERD can be significantly increased or exacerbated after $H$. pylori eradication is still controversial, probably due to the demographic or geographic differences or varying follow-up periods in the previous studies [9]. However, in Asian countries such as Japan or Korea, it has been consistently reported that eradication therapy significantly increases the risk for newly developing erosive esophagitis [2-6]. There is also an intriguing case report by Kokkola et al. [10], who described a patient having a 3-cm-long Barrett's epithelium through erosive esophagitis 5 years after spontaneous clearance of $H$. pylori.

In the current case, when esophageal adenocarcinoma was discovered, mild erosive esophagitis and hiatal hernia were concurrently present, although those findings were secondarily induced by the development of the tumor. In addition, coexistent short-segment Barrett's epithelium seen in the 11 o'clock position of the esophagogastric junction was likely to have increased its length with some squamous islands when the endoscopic views before and after eradication therapy were compared retrospectively. These observations imply that GERD was exacerbated after the successful eradication of H. pylori in our patient. Gastric acid is one of the most critically causative factors in the reflux materials for esophageal mucosal injury in GERD. As we and other investigators have reported, the recovery of gastric acid secretion after eradication is the key pathogenic factor for newly developing erosive esophagitis in addition to individual predisposition to gastroesophageal reflux such as hiatal hernia, male sex or increased body mass index $[2-6,11]$. Based on our previous report showing that gastric acid secretion significantly increases after cure of $H$. pylori infection in patients with gastric ulcer [12], the acidity of gastric acid was probably increased after eradication therapy as well in the present patient, who also suffered from gastric ulcer. Thus, it is conceivable that our patient would be the first case who newly developed esophageal adenocarcinoma through GERD after eradication therapy. The involvement of refluxed gastric acid in the carcinogenesis of Barrett's esophagus has been supported by previous in vitro and ex vivo studies, which have demonstrated that abnormal esophageal acid exposure can increase proliferation or cause DNA injury in Barrett's epithelium [13].

Successful eradication of $H$. pylori has many advantages in preventing the relapse of gastroduodenal ulcer, leading mucosa-associated lymphoid tissue lymphoma to remission status, or reducing the risk of gastric cancer [14]. On the other hand, newly developed GERD or erosive esophagitis have been reported as a potential disadvantage of $H$. pylori eradication therapy, but the majority of those conditions after eradication have been reported to be mild and not progressively exacerbated for several years [15]. Therefore, a potentially increased risk of GERD after $H$. pylori eradication therapy should not preclude the practice of eradication therapy. However, as suggested in this case report, further 
long-term follow-up will be needed in consideration of the emergence of GERD and its subsequent complications including esophageal cancer even in subjects with successful eradication of $H$. pylori.

\section{Disclosure Statement}

None of the authors discloses any financial relationships relevant to this publication.
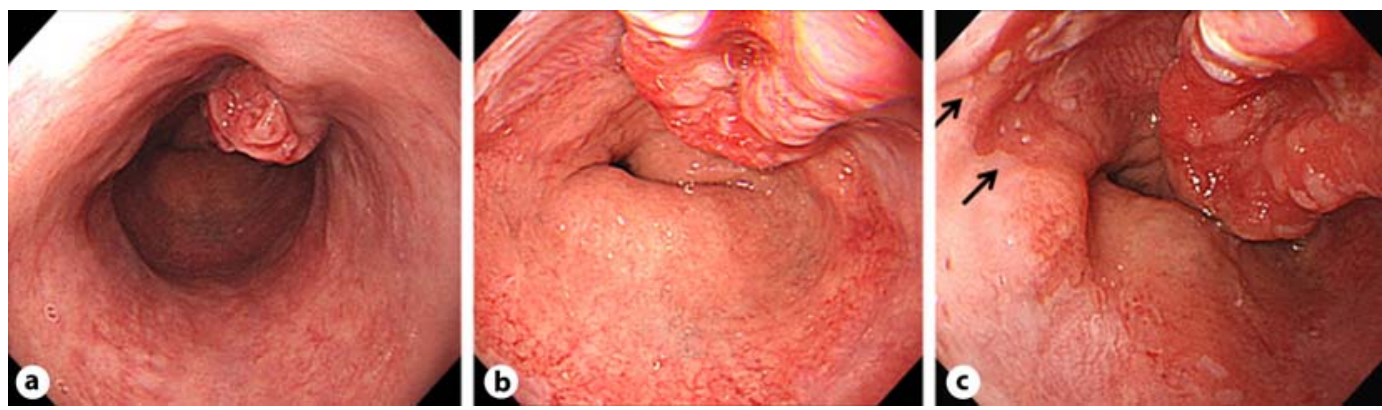

Fig. 1. a Endoscopic image of the lower esophagus. The tumor was found to be located in the 1 o'clock position of the lower end of the esophagus. $\mathbf{b}$ Endoscopic image of the esophagogastric junction. The lower margin of the tumor almost coincided with the esophagogastric junction. c Endoscopic image of the tumor and the short segment of Barrett's epithelium. A short segment of columnar lined esophagus with squamous islands (short-segment Barrett's epithelium) was observed in the 11 o'clock position of the esophagogastric junction near the tumor (arrows). 

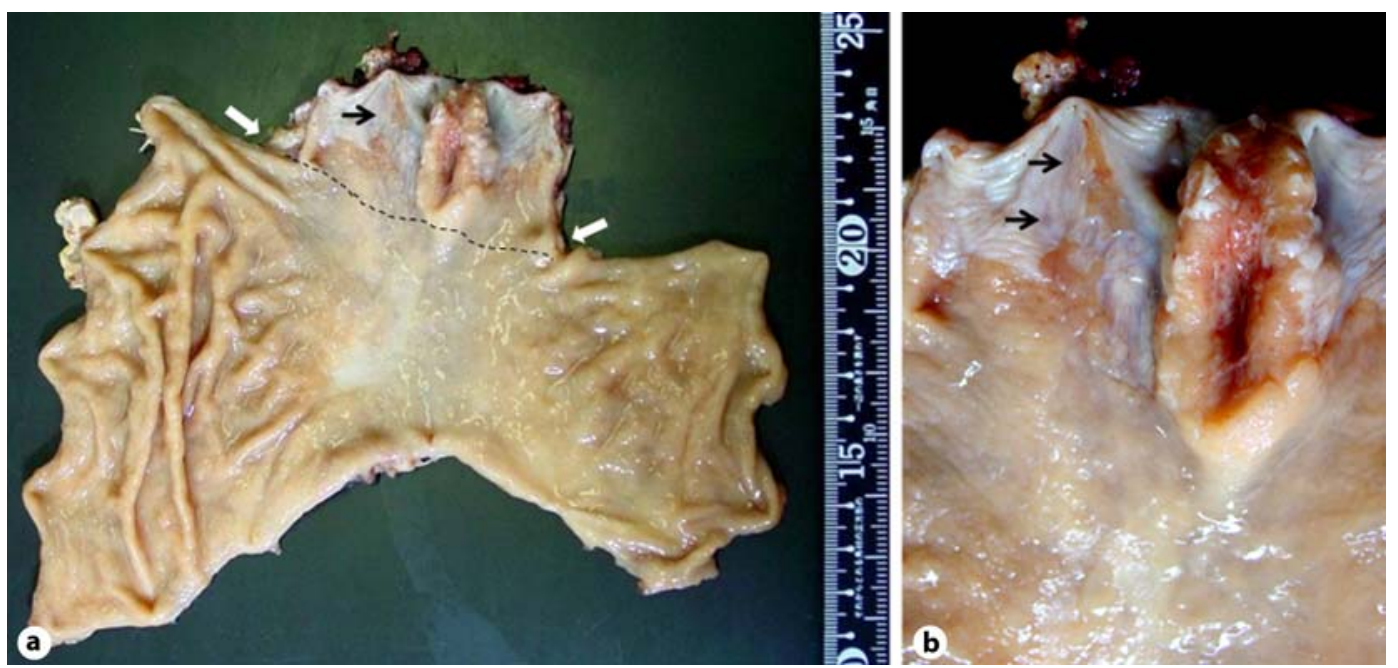

Fig. 2. a Gross image of the resected sample. The tumor was mostly localized proximally to the esophagogastric junction and the cardiac notch, which is presumptively depicted by the broken line and the white arrows, respectively. $\mathbf{b}$ Close-up image around the esophagogastric junction. As seen in endoscopy, short-segment Barrett's epithelium was observed near the tumor (black arrows), with intestinal metaplasia and submucosal esophageal glands histologically confirmed.

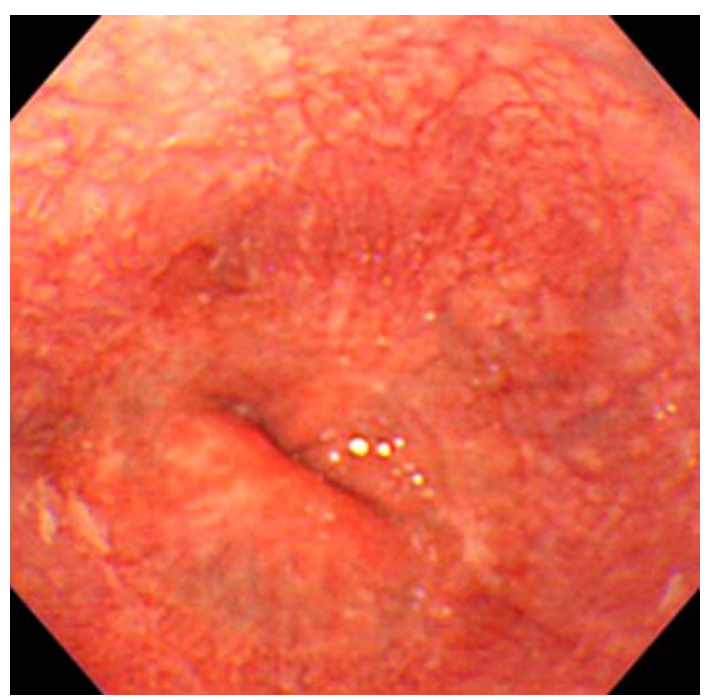

Fig. 3. Endoscopic image of the esophagogastric junction in December 2002. No apparent evidence of tumor in the lower esophagus was found in the previous endoscopic examination prior to eradication therapy. 


\begin{tabular}{r|l|l|l}
$\begin{array}{r}\text { Case Reports in } \\
\text { Gastroenter0logy }\end{array}$ & $\begin{array}{l}\text { Case Rep Gastroenterol 2011;5:355-360 } \\
\text { Dol: } 10.1159 / 000329878\end{array}$ & $\begin{array}{l}\text { Published online: } \\
\text { July 8, 2011 }\end{array}$ & $\begin{array}{l}\odot \text { 2011 S. Karger AG, Basel } \\
\text { ISSN 1662-0631 } \\
\text { www.karger.com/crg }\end{array}$ \\
\hline
\end{tabular}

\section{References}

$\longrightarrow 1$ Raghunath A, Hungin AP, Wooff D, Childs S: Prevalence of Helicobacter pylori in patients with gastrooesophageal reflux disease: systematic review. BMJ 2003;326:737.

2 Hamada H, Haruma K, Mihara M, Kamada T, Yoshihara M, Sumii K, Kajiyama G, Kawanishi M: High incidence of reflux oesophagitis after eradication therapy for Helicobacter pylori: impacts of hiatal hernia and corpus gastritis. Aliment Pharmacol Ther 2000;14:729-735.

-3 Inoue H, Imoto I, Taguchi Y, Kuroda M, Nakamura M, Horiki N, Oka S, Gabazza EC, Adachi Y: Reflux esophagitis after eradication of Helicobacter pylori is associated with the degree of hiatal hernia. Scand J Gastroenterol 2004;39:1061-1065.

4 Kawanishi M: Development of reflux esophagitis following Helicobacter pylori eradication. J Gastroenterol 2005;40:1024-1028.

5 Take S, Mizuno M, Ishiki K, Nagahara Y, Yoshida T, Yokota K, Oguma K, Okada H, Yamamoto K: Helicobacter pylori eradication may induce de novo, but transient and mild, reflux esophagitis: Prospective endoscopic evaluation. J Gastroenterol Hepatol 2009;24:107-113.

-6 Nam SY, Choi IJ, Ryu KH, Kim BC, Kim CG, Nam BH: Effect of Helicobacter pylori infection and its eradication on reflux esophagitis and reflux symptoms. Am J Gastroenterol 2010;105:2153-2162.

-7 Pisegna J, Holtmann G, Howden CW, Katelaris PH, Sharma P, Spechler S, Triadafilopoulos G, Tytgat G: Review article: oesophageal complications and consequences of persistent gastro-oesophageal reflux disease. Aliment Pharmacol Ther 2004;20(suppl 9):47-56.

8 Labenz J, Blum AL, Bayerdörffer E, Meining A, Stolte M, Börsch G: Curing Helicobacter pylori infection in patients with duodenal ulcer may provoke reflux esophagitis. Gastroenterology 1997;112:1442-1447.

-9 Yaghoobi M, Farrokhyar F, Yuan Y, Hunt RH: Is there an increased risk of GERD after Helicobacter pylori eradication? A meta-analysis. Am J Gastroenterol 2010;105:1007-1013.

10 Kokkola A, Sipponen P, Haapiainen R, Rautelin H, Karjalainen-Lindsberg ML, Puolakkainen P: Development of Barrett's esophagus after 'spontaneous' healing of atrophic corpus gastritis. Helicobacter 2003;8:590-593.

11 Koike T, Ohara S, Sekine H, Iijima K, Kato K, Toyota T, Shimosegawa T: Increased gastric acid secretion after Helicobacter pylori eradication may be a factor for developing reflux oesophagitis. Aliment Pharmacol Ther 2001;15:813-820.

12 Iijima K, Ohara S, Sekine H, Koike T, Kato K, Asaki S, Shimosegawa T, Toyota T: Changes in gastric acid secretion assayed by endoscopic gastrin test before and after Helicobacter pylori eradication. Gut 2000;46: $20-26$.

13 Zhang HY, Hormi-Carver K, Zhang X, Spechler SJ, Souza RF: In benign Barrett's epithelial cells, acid exposure generates reactive oxygen species that cause DNA double-strand breaks. Cancer Res 2009;69:9083-9089.

- 14 Malfertheiner P, Megraud F, O’Morain C, Bazzoli F, El-Omar E, Graham D, Hunt R, Rokkas T, Vakil N, Kuipers EJ: Current concepts in the management of Helicobacter pylori infection: the Maastricht III Consensus Report. Gut 2007;56:772-781.

15 Sasaki A, Haruma K, Manabe N, Tanaka S, Yoshihara M, Chayama K: Long-term observation of reflux oesophagitis developing after Helicobacter pylori eradication therapy. Aliment Pharmacol Ther 2003;17: $1529-1534$. 